\title{
MMP-3 gene polymorphisms are associated with increased risk of osteoarthritis in Chinese men
}

\author{
Wen Guo ${ }^{1,4, *}$, Pengcheng $\mathrm{Xu}^{6, *}$, Tianbo Jin ${ }^{2,3}$, Jihong Wang ${ }^{4}$, Dongsheng Fan ${ }^{4}$, \\ Zengtao Hao ${ }^{4}$, Yuntao $\mathrm{Ji}^{4}$, Shangfei Jing ${ }^{4}$, Chaoqian Han ${ }^{4}$, Jieli Du7, Dong Jiang ${ }^{1}$, \\ Shuzheng Wen ${ }^{4}$ and Jianzhong Wang ${ }^{5}$ \\ ${ }^{1}$ Inner Mongolia Medical University, Hohhot, Inner Mongolia, China \\ ${ }^{2}$ National Engineering Research Center for Miniaturized Detection Systems, School of Life Sciences, Northwest University, \\ Xi'an, Shaanxi, China \\ ${ }^{3}$ Xi'an Tiangen Precision Medical Institute, Xi'an, Shaanxi, China \\ ${ }^{4}$ Department of Hand Surgery, Hebei Province Cangzhou Hospital of Integrated Traditional and Western Medicine, Cangzhou, \\ Hebei, China \\ ${ }^{5}$ Department of Trauma, Second Affiliated Hospital, Inner Mongolia Medical University, Hohhot, Inner Mongolia Autonomous \\ Region, China \\ ${ }^{6}$ Department of Hand Surgery, Hebei province Cangzhou Hospital of integrated Traditional and Western Medicine, Cangzhou, \\ Hebei, China \\ ${ }^{7}$ Cangzhou People's Hospitial, Cangzhou, Hebei, China \\ * These authors have contributed equally to this work \\ Correspondence to: Shuzheng Wen, email: 1073117536@qq.com
}

Jianzhong Wang, email: wangjianzhong0503@126.com

Keywords: association; osteoarthritis; MMP-3; single nucleotide polymorphism

Received: December 8, $2016 \quad$ Accepted: April 26, $2017 \quad$ Published: June 15, 2017

Copyright: Guo et al. This is an open-access article distributed under the terms of the Creative Commons Attribution License 3.0 (CC BY 3.0), which permits unrestricted use, distribution, and reproduction in any medium, provided the original author and source are credited.

\section{ABSTRACT}

Osteoarthritis (OA) is the most common late-onset degenerative joint disease., It is characterized by progressive degradation of articular cartilage. We investigated the association between OA occurrence and single nucleotide polymorphisms (SNPS) in the matrix metalloproteinase-3 (MMP-3) gene involved in the breakdown of extracellular matrix proteins. The study included 100 male OA patients and 197 healthy men from the north area of China. Eight MMP-3 SNPs were genotyped. Odds ratios (ORs) with $95 \%$ confidence intervals (95\%CIs) and multivariate logistic regression analysis were used to assess the association. Multivariate logistic regression analysis was used to identify SNPs that correlated with OA susceptibility. We found that rs639752 (dominant, OR $=2.03,95 \% \mathrm{CI}: 1.03-4.01, P=0.038$; over-dominant, $\mathrm{OR}=$ 2.00, 95\% CI: $1.03-3.88, P=0.037$ ); rs520540 (dominant, OR $=2.03,95 \%$ CI: $1.03-$ 4.01, $P=0.038$; over-dominant, $\mathrm{OR}=2.00,95 \% \mathrm{CI}: 1.03-3.88, P=0.037$ ); rs602128 (dominant, $O R=2.03,95 \%$ CI: $1.03-4.01, P=0.038$; over-dominant, $O R=2.01,95 \%$ CI: $1.03-3.89, P=0.037$ ); and rs679620 (dominant, $O R=2.03,95 \%$ CI: $1.03-4.01, P$ $=0.038$; over-dominant, $\mathrm{OR}=2.04,95 \% \mathrm{CI}: 1.05-3.96, P=0.033$ ) were associated with the increased risk of OA. Our results suggest that these SNPs may contribute to OA development, and could serve as molecular markers of OA susceptibility.

\section{INTRODUCTION}

Bone and joint diseases are the most common causes of severe chronic pain and physical disability among elderly people, and affect the health of millions of people worldwide [1]. Osteoarthritis (OA), the most common late-onset degenerative joint disease, primarily affects the knees, hips, hands, and spine [2]. OA starts at weightbearing areas, but progresses to peripheral regions [3]. The prominent features of OA include progressive degradation 
of articular cartilage, accompanied with joint space narrowing, subchondral bone sclerosis, and osteophyte formation at the joint margin, resulting in chronic joint pain and restricted motion [4]. Both genetic and nongenetic factors contribute to OA initiation and progression. The non-genetic factors include obesity, history of arthrosis injury, occupational activities, sex hormones and structural changes, meniscectomy, gender, and age [5]. Genetic factors may account for 40-60\% [6]. A number of genes involved in development of knee osteoarthritis have been identified, such as GDF5 [7], ASPN [8], FRZB [9], and COL2A 1 [10]. However, the genetic etiology of OA is still not completely clear [11]. A better understanding of the genetic factors underlying the development of OA is neededso that to identify high-risk individuals for targeted screening and prevention.

Matrix metalloproteinase-3 (MMP-3), also known as stromelysin- 1 , is a member of the MMPs family, which consists of 28 zinc-dependent endopeptidases [12]. MMP3 is produced by various cell types including fibroblasts, smooth muscle cells, chondrocytes, synoviocytes, and macrophages [13-15]. under both are the pathology of (, also known as , expressed by [15]. It is involvedins' andIt is involved in the breakdown of extra-cellular matrix proteins during normal physiological processes, such as embryonic development, reproduction, and tissue remodeling, as well as in disease processes, such as arthritis $[16,17]$.

A previous study has indicated that the $-16125 \mathrm{~A} / 6 \mathrm{~A}$ polymorphism genotypes of $M M P-3$ gene promoter do not play a significant role in the OA development in Thai population [11]. rmIn this case-control study, we have analyzed whether eight single nucleotide polymorphisms (SNPs) identified in the $M M P-3$ gene are associated with OA susceptibility in men from the north area of China.

\section{RESULTS}

\section{Participant characteristics}

A total of 100 male OA patients and 197 healthy men were enrolled in our study. The mean age of the participants was $51.18 \pm 7.849$ years in the control group and $63.35 \pm 5.786$ years in the OA case group. Since there was a significant difference in age between OA patients and control subjects $(p<0.01)$, we have adjusted for age in the subsequent data analysis.

\section{Association between $M M P-3$ gene polymorphisms and $\mathrm{OA}$ risk}

Detailed information about the selected SNPs is shown in Table 1. The minor allele of each SNP was compared with the wild-type allele. All tested SNPs were in Hardy-Weinberg equilibrium (HWE) in the control group $(P>0.05)$. Comparing the differences in frequency distributions of alleles between cases and controls by $\chi^{2}$ tests, we found no correlation between the loci and the risk for OA under the allele model.

After adjusting for age, further model association analyses were performed by unconditional logistic regression analysis (Table 2). We found that rs639752 was associated with an increased OA risk by dominant (e genotype "CA-CC", OR $=2.03,95 \%$ CI: $1.03-4.01, P$ $=0.038$ ) and over-dominant model analyses ("CA", OR $=2.00,95 \%$ CI: $1.03-3.88, P=0.037)$. In the dominant and over-dominant models, rs520540 was associated with increased OA risk (dominant, "AG-AA", OR $=2.03$, 95\% CI: 1.03-4.01, $P=0.038$; over-dominant, "AG", $\mathrm{OR}=2.00,95 \%$ CI: $1.03-3.88, P=0.037)$. Rs602128 increased the risk of OA in dominant ("GA-AA", OR = 2.03, 95\% CI: 1.03-4.01, $P=0.038$ ) and over-dominant model analyses ("GA", OR $=2.01,95 \%$ CI: $1.03-3.89$, $P=0.037)$. Rs679620 was also associated with increased OA risk in dominant ("TC-TT", OR $=2.03,95 \%$ CI: 1.03 $4.01, P=0.038$ ) and over-dominant model analyses ("TC", $\mathrm{OR}=2.04,95 \% \mathrm{CI}: 1.05-3.96, P=0.033$ ). There was no association between $M M P-3$ loci and OA susceptibility using Bonferroni correction. In addition, no association was observed between SNP haplotypes and OA risk using the Wald test and unconditional multivariate regression analysis (Table 3).

\section{DISCUSSION}

In this study, we have investigated the association between SNPs in the MMP-3 gene and OA susceptibility in men from the north area of China. We have found that four SNPs (rs639752, rs520540, rs602128, and rs679620) are associated with the increased risk of $\mathrm{OA}$ in the dominant and over-dominant model.

Previous studies have indicated correlation between $M M P-3$ polymorphisms and different diseases [18-24]. Menezes-Silva et al [18] have reported that MMP-3 rs639752 and rs679620 genotypes are associated with the development of periapical lesions. In addition, Letra et al [19] have suggested that $M M P-3$ is associated with chronic periodontitis in the US (rs679620) and Brazilian (rs639752) population. Since SNP rs679620 is a missense mutation that alters the $M M P-3$ function [20], this mutation may affect bone remodeling, wound healing, as well as inflammatory responses. Indeed, h $M M P-3$ rs679620 has been associated with the increased risk of tendon pathologyat. In addition, the $M M P-3$ rs679620 variant has been shown to interact with the COL5A1 rs12722 variant to modify the risk of tendinopathy [23]. Clearly, the mechanisms of how the $M M P-3$ gene contributes to osteoarthritis are complex, and need to be clarified. 
Table 1: Basic information of candidate SNPs in this study.

\begin{tabular}{|r|l|l|l|l|l|l|l|l|l|}
\hline \multicolumn{2}{|c|}{} & Nucleotide & & Allele & \multicolumn{2}{c|}{ MAF } & \multicolumn{1}{c|}{ HW } & \multicolumn{3}{c|}{ Allele model } \\
\hline SNPs & Position & \multicolumn{1}{|c|}{ Role } & A/B & case & control & p-value & OR & 95\%CI & P-value \\
\hline rs639752 & 102707339 & Intron & C/A & 0.395 & 0.360 & 1.000 & 1.159 & $0.816-1.645$ & 0.410 \\
\hline rs650108 & 102708787 & Intron & G/A & 0.480 & 0.449 & 0.474 & 1.132 & $0.805-1.592$ & 0.477 \\
\hline rs520540 & 102709425 & Coding exon & A/G & 0.395 & 0.360 & 1.000 & 1.159 & $0.816-1.645$ & 0.410 \\
\hline rs646910 & 102709522 & Intron (boundary) & A/T & 0.075 & 0.089 & 1.000 & 0.832 & $0.443-1.562$ & 0.566 \\
\hline rs602128 & 102713465 & Coding exon & A/G & 0.395 & 0.359 & 1.000 & 1.166 & $0.821-1.656$ & 0.391 \\
\hline rs679620 & 102713620 & Coding exon & T/C & 0.395 & 0.363 & 1.000 & 1.146 & $0.808-1.626$ & 0.445 \\
\hline rs678815 & 102713777 & Intron & G/C & 0.357 & 0.360 & 1.000 & 0.986 & $0.676-1.437$ & 0.941 \\
\hline rs522616 & 102715048 & Promoter & C/T & 0.350 & 0.352 & 0.756 & 0.991 & $0.694-1.416$ & 0.961 \\
\hline
\end{tabular}

SNPs: Single nucleotide polymorphisms; MAF: Minor allele frequency; HWE: Hardy-Weinberg equilibrium; OR: Odds ratio; CI: Confidence interval. A: Minor alleles. B: Major alleles.

Table 2: Single loci association with OA (adjusted by age).

\begin{tabular}{|c|c|c|c|c|c|c|c|c|}
\hline SNPs & Model & Genotype & Controls(n\%) & $\operatorname{Cases}(n \%)$ & OR $(95 \%$ CI $)$ & $P$-value & AIC & BIC \\
\hline \multirow[t]{10}{*}{ rs639752 } & Codominant & $\mathrm{A} / \mathrm{A}$ & $80(40.6 \%)$ & $34(34 \%)$ & $1[\mathrm{Ref}]$ & & & \\
\hline & & $\mathrm{C} / \mathrm{A}$ & $92(46.7 \%)$ & $53(53 \%)$ & $2.23(1.08-4.59)$ & 0.085 & 236.4 & 251.2 \\
\hline & & $\mathrm{C} / \mathrm{C}$ & $25(12.7 \%)$ & $13(13 \%)$ & $1.50(0.54-4.13)$ & & & \\
\hline & Dominant & $\mathrm{A} / \mathrm{A}$ & $80(40.6 \%)$ & $34(34 \%)$ & $1[\mathrm{Ref}]$ & & & \\
\hline & & $\mathrm{C} / \mathrm{A}-\mathrm{C} / \mathrm{C}$ & $117(59.4 \%)$ & $66(66 \%)$ & $2.03(1.03-4.01)$ & $0.038 *$ & 235 & 246.1 \\
\hline & Recessive & $\mathrm{A} / \mathrm{A}-\mathrm{C} / \mathrm{A}$ & $172(87.3 \%)$ & $87(87 \%)$ & $1[\mathrm{Ref}]$ & & & \\
\hline & & $\mathrm{C} / \mathrm{C}$ & $25(12.7 \%)$ & $13(13 \%)$ & $0.96(0.38-2.43)$ & 0.940 & 239.3 & 250.4 \\
\hline & $\begin{array}{l}\text { Over- } \\
\text { dominant }\end{array}$ & $\mathrm{A} / \mathrm{A}-\mathrm{C} / \mathrm{C}$ & $105(53.3 \%)$ & $47(47 \%)$ & $1[\mathrm{Ref}]$ & & & \\
\hline & & $\mathrm{C} / \mathrm{A}$ & $92(46.7 \%)$ & $53(53 \%)$ & $2.00(1.03-3.88)$ & $0.037 *$ & 235 & 246.1 \\
\hline & Log-additive & --- & --- & --- & $1.41(0.88-2.26)$ & 0.150 & 237.3 & 248.4 \\
\hline \multirow[t]{10}{*}{ rs520540 } & Codominant & $\mathrm{G} / \mathrm{G}$ & $80(40.6 \%)$ & $34(34 \%)$ & $1[\mathrm{Ref}]$ & & & \\
\hline & & $\mathrm{A} / \mathrm{G}$ & $92(46.7 \%)$ & $53(53 \%)$ & $2.23(1.08-4.59)$ & 0.085 & 236.4 & 251.2 \\
\hline & & $\mathrm{A} / \mathrm{A}$ & $25(12.7 \%)$ & $13(13 \%)$ & $1.50(0.54-4.13)$ & & & \\
\hline & Dominant & $\mathrm{G} / \mathrm{G}$ & $80(40.6 \%)$ & $34(34 \%)$ & $1[\mathrm{Ref}]$ & & & \\
\hline & & $\mathrm{A} / \mathrm{G}-\mathrm{A} / \mathrm{A}$ & $117(59.4 \%)$ & $66(66 \%)$ & $2.03(1.03-4.01)$ & $0.038 *$ & 235 & 246.1 \\
\hline & Recessive & G/G-A/G & $172(87.3 \%)$ & $87(87 \%)$ & $1[$ Ref] & & & \\
\hline & & $\mathrm{A} / \mathrm{A}$ & $25(12.7 \%)$ & $13(13 \%)$ & $0.96(0.38-2.43)$ & 0.940 & 239.3 & 250.4 \\
\hline & $\begin{array}{l}\text { Over- } \\
\text { dominant }\end{array}$ & G/G-A/A & $105(53.3 \%)$ & $47(47 \%)$ & $1[\mathrm{Ref}]$ & & & \\
\hline & & $\mathrm{A} / \mathrm{G}$ & $92(46.7 \%)$ & $53(53 \%)$ & $2.00(1.03-3.88)$ & $0.037 *$ & 235 & 246.1 \\
\hline & Log-additive & -- & --- & --- & $1.41(0.88-2.26)$ & 0.150 & 237.3 & 248.4 \\
\hline \multirow[t]{5}{*}{ rs602128 } & Codominant & $\mathrm{G} / \mathrm{G}$ & $80(41 \%)$ & $34(34 \%)$ & $1[\mathrm{Ref}]$ & & & \\
\hline & & $\mathrm{G} / \mathrm{A}$ & $90(46.1 \%)$ & $53(53 \%)$ & $2.24(1.09-4.60)$ & 0.084 & 236.3 & 251 \\
\hline & & $\mathrm{A} / \mathrm{A}$ & $25(12.8 \%)$ & $13(13 \%)$ & $1.49(0.54-4.12)$ & & & \\
\hline & Dominant & $\mathrm{G} / \mathrm{G}$ & $80(41 \%)$ & $34(34 \%)$ & $1[$ Ref $]$ & & & \\
\hline & & G/A-A/A & $115(59 \%)$ & $66(66 \%)$ & $2.03(1.03-4.01)$ & $0.038 *$ & 234.9 & 246 \\
\hline
\end{tabular}




\begin{tabular}{|l|l|c|c|c|c|c|c|c|}
\hline & Recessive & G/G-G/A & $170(87.2 \%)$ & $87(87 \%)$ & $1[\mathrm{Ref}]$ & & & \\
\hline & & $\mathrm{A} / \mathrm{A}$ & $25(12.8 \%)$ & $13(13 \%)$ & $0.96(0.38-2.42)$ & 0.940 & 239.2 & 250.3 \\
\hline & $\begin{array}{l}\text { Over- } \\
\text { dominant }\end{array}$ & $\mathrm{G} / \mathrm{G}-\mathrm{A} / \mathrm{A}$ & $105(53.9 \%)$ & $47(47 \%)$ & $1[\mathrm{Ref}]$ & & & \\
\hline & & $\mathrm{G} / \mathrm{A}$ & $90(46.1 \%)$ & $53(53 \%)$ & $2.01(1.03-3.89)$ & $0.037 *$ & 234.9 & 245.9 \\
\hline & Log-additive & --- & --- & --- & $1.41(0.88-2.26)$ & 0.150 & 237.2 & 248.3 \\
\hline rs679620 & Codominant & $\mathrm{C} / \mathrm{C}$ & $80(40.6 \%)$ & $34(34 \%)$ & $1[\mathrm{Ref}]$ & & & \\
\hline & & $\mathrm{T} / \mathrm{C}$ & $91(46.2 \%)$ & $53(53 \%)$ & $2.26(1.10-4.66)$ & 0.078 & 236.2 & 251 \\
\hline & & $\mathrm{T} / \mathrm{T}$ & $26(13.2 \%)$ & $13(13 \%)$ & $1.45(0.53-3.98)$ & & & \\
\hline & Dominant & $\mathrm{C} / \mathrm{C}$ & $80(40.6 \%)$ & $34(34 \%)$ & $1[\mathrm{Ref}]$ & & & \\
\hline & & $\mathrm{T} / \mathrm{C}-\mathrm{T} / \mathrm{T}$ & $117(59.4 \%)$ & $66(66 \%)$ & $2.03(1.03-4.01)$ & $0.038^{*}$ & 235 & 246.1 \\
\hline & Recessive & $\mathrm{C} / \mathrm{C}-\mathrm{T} / \mathrm{C}$ & $171(86.8 \%)$ & $87(87 \%)$ & $1[\mathrm{Ref}]$ & & & \\
\hline & & $\mathrm{T} / \mathrm{T}$ & $26(13.2 \%)$ & $13(13 \%)$ & $0.93(0.37-2.32)$ & 0.880 & 239.3 & 250.4 \\
\hline & $\begin{array}{l}\text { Over- } \\
\text { dominant }\end{array}$ & $\mathrm{C} / \mathrm{C}-\mathrm{T} / \mathrm{T}$ & $106(53.8 \%)$ & $47(47 \%)$ & $1[\mathrm{Ref}]$ & & & \\
\hline & & $\mathrm{T} / \mathrm{C}$ & $91(46.2 \%)$ & $53(53 \%)$ & $2.04(1.05-3.96)$ & $0.033 *$ & 234.8 & 245.8 \\
\hline & Log-additive & --- & --- & --- & $1.39(0.87-2.22)$ & 0.170 & 237.4 & 248.5 \\
\hline
\end{tabular}

SNPs: Single nucleotide polymorphisms; OR: Odds ratio. CI: Confidence interval.

$P$-value was calculated by Wald test. ${ }^{*} p$-value $<0.05$ indicates statistically significant.

Table 3: Haplotype frequencies and their association with $O A$ risk in case and control subjects.

\begin{tabular}{|l|l|l|l|l|l|l|l|l|}
\hline & & \multicolumn{2}{l|}{ Frequency } & \multicolumn{2}{l|}{ Without adjustment } & \multicolumn{2}{l|}{ With adjustment } \\
\hline SNPs & Haplotype & case & control & OR(95\% CI) & $\boldsymbol{P}^{\mathbf{a}}$ & OR(95\% CI) & $\boldsymbol{P}^{\mathbf{b}}$ \\
\hline rs639752/rs650108/rs520540 & CGATATGT & 0.395 & 0.360 & $1[\mathrm{Ref}]$ & --- & $1[\operatorname{Ref}]$ & --- \\
\hline /rs646910/rs602128/rs679620 & AAGTGCCC & 0.345 & 0.352 & $0.90(0.60-1.35)$ & 0.61 & $0.77(0.46-1.31)$ & 0.33 \\
\hline /rs678815/rs522616 & AAGTGCCT & 0.175 & 0.199 & $0.81(0.49-1.34)$ & 0.41 & $0.72(0.37-1.43)$ & 0.35 \\
\hline & AGGAGCCT & 0.075 & 0.089 & $0.78(0.40-1.53)$ & 0.47 & $0.47(0.19-1.16)$ & 0.10 \\
\hline
\end{tabular}

OR: odd ratio; CI: confidence interval.

$P$-value $<0.05$ indicates statistical significance.

$P^{a}$ values were calculated from two-side Chi-square tests.

$P^{b}$ values were calculated by unconditional logistic regression adjusted for age.

To the best of our knowledge, this is the first study indicating an association between $M M P-3$ polymorphism and OA susceptibility. Although this study had a sufficient statistical power, there are some limitations. First, the sample size was not sufficient for association studies (100 cases and 197controls). Therefore, our findings must be confirmed in larger datasets as well as in a meta-analysis. Additionally, our study included only Han Chinese men. Epidemiological studies have demonstrated significantly increased occurrence of primary osteoarthritis in women compared to men [25], suggesting that the increased OA incidence might be caused by decreased estrogen levels in elderly women. Since we wanted to exclude the influence of estrogen, we have included only men in this study. Future studies should address the sex differences in the genetics of OA, as well as the effect of obesity, history of arthrosis injury, occupational activities, sex hormones, and structural changes. The fact that we have found no statistically significant association between $M M P-3$ SNPs and OA susceptibility using Bonferroni correction may be caused by the relatively small sample size, the selection criteria for MMP-3 SNPs (MAF > 5\%), and the weakness of Bonferroni correction itself. True differences may have been deemed non-significant due to the type II errors.

In conclusion, our study has revealed a significant association between four polymorphisms (rs639752, rs520540, rs602128, and rs679620) in the $M M P-3$ gene and increased risk of $\mathrm{OA}$ in men from the north area of China. Our results suggest that these SNPs may contribute to the OA development, and serve as molecular markers of OA susceptibility. 
Table 4: Primers used for this study.

\begin{tabular}{|l|l|l|l|}
\hline \multicolumn{1}{|c|}{ SNP_ID } & \multicolumn{1}{|c|}{ 1st-PCRP } & \multicolumn{1}{c|}{ 2nd-PCRP } & \multicolumn{1}{c|}{ UEP_SEQ } \\
\hline rs639752 & ACGTTGGATGCAGATAAATTCTCCACTTGC & $\begin{array}{l}\text { ACGTTGGATGGGCTGCAATGC } \\
\text { GGGAAAAG }\end{array}$ & tGGGAAGAAAGAAATAGGTGAT \\
\hline rs650108 & ACGTTGGATGGTCACTGTCTCATTGTGTGT & ACGTTGGATGTCAGGTAGAGGTGACAAGTG & tAAGTGGGTGAGGTTAGA \\
\hline rs520540 & ACGTTGGATGGCGAAAGGGCTTAACTGTTAT & ACGTTGGATGCCAGCTCGTACCTCATTTCC & CTCGTACCTCATTTCCTCTGAT \\
\hline rs646910 & ACGTTGGATGCCACTGTAAGCTGGTGACTA & ACGTTGGATGGTTAAGCCCTTTCGCTTTAG & CGCTTTAGAAATACACTTTAGCATCT \\
\hline rs602128 & ACGTTGGATGCTTCGGGATGCCAGGAAA & ACGTTGGATGAAGCTGGACTCCGACACTCT & CAGGTGTGGAGTTCCTGA \\
\hline rs679620 & ACGTTGGATGAACAGGACCACTGTCCTTTC & ACGTTGGATGAGAAATATCTAGAAAACTAC & tcTCTAGAAAACTACTACGACCTC \\
\hline rs678815 & ACGTTGGATGAATGCAACGTAATTTTAGC & ACGTTGGATGTGGAGTATTTCTCTAGCTTG & TCTCTAGCTTGCTGAAATAATG \\
\hline rs522616 & ACGTTGGATGCGTAGCTGCTCCATAAATAG & ACGTTGGATGACAGAGAGAATTTCAGTCCG & gaCGGTAAGCAATGTAATTCATTTCA \\
\hline
\end{tabular}

\section{MATERIALS AND METHODS}

\section{Study participants}

From January 2014 to July 2016, we recruited 100 male OA patients and 197 healthy men in this study. The patients were treated at the First Department of Trauma $\&$ Second Hand and Foot Surgery, Second Affiliated Hospital, Inner Mongolia Medical University, China. All demographic and clinical data including residential region, age, ethnicity, and education status were collected through a face-to-face questionnaire and a review of medical records. Patients recently diagnosed with primary OA were included in the study. The diagnosis criteria of OA were based on the American College of Rheumatology, and included primary OA with symptoms and radiographic signs of OA according to the Kellgren-Lawrence grading system [26]. The controls were recruited from Physical Examination Center in the first Affiliated Hospital, Inner Mongolia Medical University, China, and had no personal or family history of OA. Participants were excluded on the basis of having arthropathy due to gout, pseudogout, rheumatoid arthritis (RA), systemic lupus erythematosus, psoriasis, hemochromatosis, previous knee injury, or previous joint infection. In addition, patients with any systemic inflammatory or autoimmune disorder, or any type of malignant or chronic illness were not included in this study.

This study was performed in accordance with the Chinese Department of Health and Human Services regulations for the protection of human research subjects. Informed consents were obtained from all participants and the study protocols were approved by the Institutional Review Board of Inner Mongolia Medical University.

\section{SNP selection and genotyping}

Validated SNPs, associated with other diseases in previous studies, were selected with a minor allele frequency $(\mathrm{MAF})>5 \%$ in the HapMap Asian population
[13, 18, 21, 27-29]. After recruitment, venous blood samples $(5 \mathrm{~mL})$ were collected from each patient during a laboratory examination. DNA was extracted from whole blood samples using the Gold Mag-Mini Whole Blood Genomic DNA Purification Kit (GoldMag Ltd., $\mathrm{Xi}$ 'an, China) and stored at $-80^{\circ} \mathrm{C}$ after centrifugation. The Sequenom MassARRAY Assay Design 3.0 software (Sequenom, Inc, San Diego, CA, USA) was used to design the multiplexed SNP Mass EXTEND assay. Genotyping was performed using a Sequenom MassARRAY RS1000 (Sequenom, Inc.) according to the manufacturer's protocol [30]. The SequenomTyper 4.0 Software ${ }^{\mathrm{TM}}$ (Sequenom, Inc.) was used to analyze the data [31]. The primers corresponding to each SNP are shown in Table 4. The following eight SNPs in MMP-3 gene were selected: rs639752, rs650108, rs520540, rs646910, rs602128, rs679620, rs678815, and rs522616. The SNP data are shown in Table 1.

\section{Statistical analysis}

We used Chi-squared test to compare the distribution of categorical variables and Student's t-test to compare continuous variables [32]. The Hardy-Weinberg equilibrium (HWE) of each SNP was assessed in order to compare the expected frequencies of the genotypes in the control groups. The minor allele was regarded as a risk allele for OA susceptibility. Allele frequencies and genotype frequencies for each SNP of OA patients and control subjects were compared using $\chi^{2}$ test. Odds ratios (ORs) and 95\% confidence intervals (CIs) were tested by unconditional logistic regression analysis to evaluate the SNPs' effects on the risk of OA in the five models (codominant, dominant, recessive, over-dominant and logadditive). All statistical analyses were performed using SPSS version 17.0 statistical package (SPSS, Chicago, IL, USA) and Microsoft Excel (Microsoft, Redmond, WA, USA). A $p<0.05$ was considered statistically significant and all statistical tests were two-sided. Haploview software package (version4.2) and SHEsis software platform (http://www.nhgg.org/analysis/) were used to 
analyze linkage disequilibrium, haplotype construction, and genetic association at polymorphism loci. Bonferroni correction was used to adjust for multiple tests.

\section{Abbreviations}

SNP: single nucleotide polymorphism; MMP3: matrix metalloproteinase-3; OA: osteoarthritis; MAF: minor allele frequencies; HWE: Hardy-Weinberg Equilibrium; OR: odds ratio; CI: confidence interval.

\section{CONFLICTS OF INTEREST}

The authors declare no conflict of interest.

\section{ACKNOWLEDGMENTS}

We are grateful to all participants in the study and thank the clinicians and hospital staff who contributed to sample and data collection for this study. This work was supported by the National Natural Science Foundation of China (No. 81160228, 81260284 and 81660378).

\section{REFERENCES}

1. Zhang J, Song L, Liu G, Zhang A, Dong H, Liu Z, Li X, Luo J. Risk factors for and prevalence of knee osteoarthritis in the rural areas of Shanxi Province, North China: a COPCORD study. Rheumatology international. 2013; 33:2783-2788.

2. Felson DT, Zhang Y. An update on the epidemiology of knee and hip osteoarthritis with a view to prevention. Arthritis and rheumatism. 1998; 41:1343-1355.

3. Roach HI, Yamada N, Cheung KS, Tilley S, Clarke NM, Oreffo RO, Kokubun S, Bronner F. Association between the abnormal expression of matrix-degrading enzymes by human osteoarthritic chondrocytes and demethylation of specific $\mathrm{CpG}$ sites in the promoter regions. Arthritis and rheumatism. 2005; 52:3110-3124.

4. Loughlin J. Familial inheritance of osteoarthritis: documented family subsets. Clinical orthopaedics and related research. 2004; S22-25.

5. Ren Y, Tan B, Yan P, You Y, Wu Y, Wang Y. Association between polymorphisms in the estrogen receptor alpha gene and osteoarthritis susceptibility: a meta- analysis. BMC musculoskeletal disorders. 2015; 16:44.

6. Spector TD, Cicuttini F, Baker J, Loughlin J, Hart D. Genetic influences on osteoarthritis in women: a twin study. BMJ (Clinical research ed). 1996; 312:940-943.

7. Chapman K, Takahashi A, Meulenbelt I, Watson C, Rodriguez-Lopez J, Egli R, Tsezou A, Malizos KN, Kloppenburg M, Shi D, Southam L, van der Breggen R, Donn R, et al. A meta- analysis of European and Asian cohorts reveals a global role of a functional SNP in the 5'
UTR of GDF5 with osteoarthritis susceptibility. Human molecular genetics. 2008; 17:1497-1504.

8. Nakamura T, Shi D, Tzetis M, Rodriguez-Lopez J, Miyamoto Y, Tsezou A, Gonzalez A, Jiang Q, Kamatani $\mathrm{N}$, Loughlin J, Ikegawa S. Meta-analysis of association between the ASPN D-repeat and osteoarthritis. Human molecular genetics. 2007; 16:1676-1681.

9. Valdes AM, Loughlin J, Oene MV, Chapman K, Surdulescu GL, Doherty M, Spector TD. Sex and ethnic differences in the association of ASPN, CALM1, COL2A1, COMP, and FRZB with genetic susceptibility to osteoarthritis of the knee. Arthritis and rheumatism. 2007; 56:137-146.

10. Galvez-Rosas A, Gonzalez-Huerta C, Borgonio-Cuadra VM, Duarte-Salazar C, Lara-Alvarado L, de los Angeles Soria-Bastida M, Cortes-Gonzalez S, Ramon-Gallegos E, Miranda-Duarte A. A COL2A1 gene polymorphism is related with advanced stages of osteoarthritis of the knee in Mexican Mestizo population. Rheumatology international. 2010; 30:1035-1039.

11. Honsawek S, Malila S, Yuktanandana P, Tanavalee A, Deepaisarnsakul B, Parvizi J. Association of MMP- 3 (-1612 5A/6A) polymorphism with knee osteoarthritis in Thai population. Rheumatology international. 2013; 33:435-439.

12. Murphy G, Docherty AJ. The matrix metalloproteinases and their inhibitors. American journal of respiratory cell and molecular biology. 1992; 7:120-125.

13. Kim SK, Kang SW, Kim DH, Yun DH, Chung JH, Ban JY. Matrix metalloproteinase-3 gene polymorphisms are associated with ischemic stroke. Journal of interferon \& cytokine research. 2012; 32:81- 86.

14. Parsons SL, Watson SA, Brown PD, Collins HM, Steele RJ. Matrix metalloproteinases. The British journal of surgery. 1997; 84:160-166.

15. Inoue $\mathrm{K}$, Masuko-Hongo $\mathrm{K}$, Okamoto $\mathrm{M}$, Nishioka $\mathrm{K}$. Induction of vascular endothelial growth factor and matrix metalloproteinase-3 (stromelysin) by interleukin-1 in human articular chondrocytes and synoviocytes. Rheumatology international. 2005; 26:93-98.

16. Arthur MJ. Fibrogenesis II. Metalloproteinases and their inhibitors in liver fibrosis. American journal of physiology Gastrointestinal and liver physiology. 2000; 279:G245-249.

17. Woessner JF Jr. Matrix metalloproteinases and their inhibitors in connective tissue remodeling. FASEB journal. 1991; 5:2145-2154.

18. Menezes-Silva R, Khaliq S, Deeley K, Letra A, Vieira AR. Genetic susceptibility to periapical disease: conditional contribution of MMP2 and MMP3 genes to the development of periapical lesions and healing response. Journal of endodontics. 2012; 38:604-607.

19. Letra A, Silva RM, Rylands RJ, Silveira EM, de Souza AP, Wendell SK, Garlet GP, Vieira AR. MMP3 and TIMP1 variants contribute to chronic periodontitis and may be implicated in disease progression. Journal of clinical 
periodontology. 2012; 39:707-716.

20. Taylor J, Sun YV, Chu J, Mosley TH, Kardia SL. Interactions between metallopeptidase 3 polymorphism rs679620 and BMI in predicting blood pressure in African-American women with hypertension. Journal of hypertension. 2008; 26:2312-2318.

21. Shibata N, Ohnuma T, Higashi S, Usui C, Ohkubo T, Kitajima A, Ueki A, Nagao M, Arai H. Genetic association between matrix metalloproteinase MMP-9 and MMP-3 polymorphisms and Japanese sporadic Alzheimer's disease. Neurobiology of aging. 2005; 26:1011-1014.

22. Foster BP, Morse CI, Onambele GL, Williams AG. Erratum to: variants within the MMP3 gene and patellar tendon properties in vivo in an asymptomatic population. European journal of applied physiology. 2015; 115:861.

23. Raleigh SM, van der Merwe L, Ribbans WJ, Smith RK, Schwellnus MP, Collins M. Variants within the MMP3 gene are associated with Achilles tendinopathy: possible interaction with the COL5A1 gene. British journal of sports medicine. 2009; 43:514-520.

24. Gibbon A, Hobbs H, van der Merwe W, Raleigh SM, Cook J, Handley CJ, Posthumus M, Collins M, September AV. The MMP3 gene in musculoskeletal soft tissue injury risk profiling: A study in two independent sample groups. Journal of sports sciences. 2016; 35: 1-8.

25. Lawrence RC, Helmick CG, Arnett FC, Deyo RA, Felson DT, Giannini EH, Heyse SP, Hirsch R, Hochberg MC, Hunder GG. Estimates of the prevalence of arthritis and selected musculoskeletal disorders in the United States. Arthritis \& Rheumatology. 1998; 41:778-799.

26. Kellgren JH, Lawrence JS. Radiological assessment of osteo-arthrosis. Annals of the rheumatic diseases. 1957; 16:494-502.
27. Xu Q, Gai PY, Lv HL, Li GR, Liu XY. Association of MMP3 genotype with susceptibility to frozen shoulder: a case-control study in a Chinese Han population. Genetics and molecular research. 2016; 15.

28. Cugino D, Gianfagna F, Ahrens W, De Henauw S, Koni AC, Marild S, Molnar D, Moreno LA, Pitsiladis Y, Russo P, Siani A, Tornaritis M, Veidebaum T, et al. Polymorphisms of matrix metalloproteinase gene and adiposity indices in European children: results of the IDEFICS study. International journal of obesity. 2013; 37:1539-1544.

29. Ma AJ, Fan LY, Li WJ, Zhao HQ, Han Y, Jiang XS, Yi P, Li CL, Song S, Ma CL, Yao RY, Pan XD. Association of matrix metalloproteinase-3 gene polymorphisms with subtypes of ischemic stroke. [Article in Chinese]. Chinese journal of medical genetics. 2013; 30:461-466.

30. Gabriel S, Ziaugra L, Tabbaa D. SNP genotyping using the Sequenom MassARRAY iPLEX platform. Current protocols in human genetics / editorial board, Jonathan L Haines [et al]. 2009; Chapter 2:Unit 2.12.

31. Thomas RK, Baker AC, Debiasi RM, Winckler W, Laframboise T, Lin WM, Wang M, Feng W, Zander T, MacConaill L, Lee JC, Nicoletti R, Hatton C, et al. Highthroughput oncogene mutation profiling in human cancer. Nature genetics. 2007; 39:347-351.

32. Adamec C. [EXAMPLE OF THE USE OF THE NONPARAMETRIC TEST. TEST X2 FOR COMPARISON OF 2 INDEPENDENT EXAMPLES]. [Article in Czech]. Ceskoslovenske zdravotnictvi. 1964; 12:613-619. 